\author{
ZBYSZKO MELOSIK \\ ORCID 0000-0002-7802-3152 \\ Uniwersytet im. Adama Mickiewicza \\ $w$ Poznaniu
}

\title{
PIĘKNO I ESTETYKA W MATEMATYCE
}

\begin{abstract}
Melosik Zbyszko, Piękno i estetyka w matematyce [Beauty and Aesthetics in Mathematics]. Studia Edukacyjne nr 60, 2021, Poznań 2021, pp. 103-112. Adam Mickiewicz University Press. ISSN 1233-6688. DOI: $10.14746 /$ se.2021.60.6

The article is devoted to the concept of beauty and aesthetics in mathematics. It first analyses the assumptions of rationality and objectivity of mathematics. In the second part, the article addresses the beauty and aesthetics in mathematical thinking and indicates profound skepticism in their validity. It likewise reconstructs the aesthetic dimension of Einstein's theory. At the end, the author considers his own approach to aesthetics of theory in social sciences.
\end{abstract}

Key words: mathematics, beauty, aesthetics, rationality

Carl Friedrich Gauss nazwał matematykę „królową nauk”; niekiedy mówi się, że znajduje się ona na "szczycie hierarchii nauk"1 (uważa się nawet, że „Bóg jest matematykiem”2). Jednocześnie, w powszechnej opinii, nauka ta stanowi, obok fizyki, symbol obiektywizmu naukowego. Uważa się, że odkrycia matematyki są „ostateczne”, niepodważalne, jak również nie są podatne na różnorodne, a tym bardziej sprzeczne ze sobą interpretacje.

Matematyka akademicka wpisuje się więc bez wątpienia $\mathrm{w}$ tę tradycję uprawiania zachodniej nauki, u podstaw której znajduje się kategoria racjonalności. Charlotte Bloch ujmuje to w sposób następujący: „Świat uniwersytecki jest generalnie związany z racjonalnością, założeniami metodologicznymi, obiektywnością i logiczną argumentacją" ${ }^{\prime \prime}$.

W takim podejściu piękno i estetyka nie mają nic wspólnego z myśleniem naukowym i tworzeniem teorii naukowych. Logicznie też, większość

${ }^{1}$ H.J.M. Bos, Lectures in the History of Mathematics, Providence 1993, s. 173.

2 Por. np. rozważania M. Livio, Is God a Mathematician?, New York 2009, s. 3.

${ }^{3}$ C. Bloch, Passion and Paranoia: Emotions and the Culture of Emotions in Academia, London - New York 2016, s. 2. 
naukowców przyjmuje jakiekolwiek „preferencje estetyczne jako nieodwołalnie przesycone emocjami (... $)^{\prime 4}$. Uważa się, że jedynym kryterium akceptacji teorii są dane empiryczne, a Dean K. Simonton napisał: „żaden naukowiec nie odważyłby się na uprawomocnianie teorii na tak irracjonalnej podstawie, jaką jest "piękno»"

A jednak kryteria estetyczne, w tym kryterium piękna jest często w nauce uznawane. I co ciekawe, większość współczesnych dyskusji dotyczących tych kryteriów w odniesieniu do teorii naukowej odnosi się do nauk ścisłych, szczególnie matematyki i fizyki. I to właśnie piękno oraz estetyka teorii matematycznych będzie przedmiotem moich rozważań w tym artykule.

Na wstępie przywołam tutaj pogląd Jamesa W. McAllistera przytaczającego słowa, które wypowiedział znany matematyk Godfrey Harold Hardy:

wzór wyprowadzony przez matematyka, jak dzieło malarza czy poety musi być piękny; idee, podobnie, jak kolory czy słowa muszą łączyć się ze sobą w harmonijny sposób. Piękno jest pierwszym testem ${ }^{6}$.

Alain Baidou pisze o zdumieniu „ostatecznym pięknem matematyki” w momencie dokonywania odkrycia7. Z kolei Dražen Barković pisze: „mate-

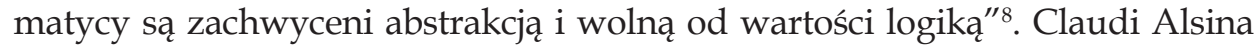
i Roger B. Nelsen uważają, że większość matematyków dąży do jak najpiękniejszego dowodzenia swoich twierdzeñ ${ }^{9}$.Według Bertranda Russella, „matematyka zawiera w sobie nie tylko prawdę, ale najwyższe piękno - piękno zimne i ascetyczne" ${ }^{\prime 10}$. W odniesieniu do matematyki James W. McAllister wyróżnia takie kryteria estetyczne, jak na przykład prostota czy symetria ${ }^{11}$. Również wielu matematyków postrzega estetyczność matematyki w kontekście pojęcia prostoty twierdzeń i sposobów dowodzenia ${ }^{12}$; również pojęcie symetrii jest często

${ }^{4}$ J.W. McAllister, Beauty and Revolution in Sience, New York 1996, s. 8; poglądy i przywołania J.W. McAllistera i S. Chandrasekhara przedstawiałem wcześniej w książce: Z. Melosik, Pasja i tożsamość naukowca. O władzy i wolności umystu, Poznań 2019.

${ }^{5}$ Podaję za: J.W. McAllister, Beauty and Revolution, s. 13.

${ }^{6}$ J.W. McAllister, Truth and Beauty in Scientific Reason, Synthesis, 1989, 78, s. 28; adres internetowy: https://openaccess.leidenuniv.nl/bitstream/handle/1887/8123/9_057_017.pdf;sequence $=1$.

7 A. Baidou, The Praise of Mathematics, Cambridge 2016, s. 4.

${ }^{8}$ D. Barković, Challenges of Interdiscyplinary Research, Interdiscyplinary Management Research, 2010, 6, s. 954.

${ }^{9}$ C. Alsina, R.B. Nelsen, Charming Proofs: A Journey Into Elegant Mathematics, printed in U.S., 2010, s. 91.

${ }^{10}$ U. Montano, Explaining Beauty in Mathematics: An Aesthetic Theory of Mathematics, Cham 2014, s. 11.

${ }^{11}$ J.W. McAllister, Mathematical beauty and the evolution of the standards of mathematical proof, [w:] The Visual Mind II, red. M. Emmer, Cambridge 2005, s. 15.

${ }_{12}$ N. Sinclair, Mathematics and Beauty. Aesthetic Approach to Teaching Children, New York 2006, s. 67. 
eksponowane ${ }^{13}$. J.D. Phillips uważa, że ,jedną z najbardziej urzekających cech estetycznych matematyki jest jej wyrafinowana prostota $(. . .)^{\prime 14}$. Także według niemieckiego matematyka Hermanna Weyla, podstawą uporządkowania, doskonałości i piękna w matematyce jest symetria. Podobnie ujmuje tę kwestię G.I. Sarantsev, twierdząc, że estetykę matematyki tworzy uporządkowanie, rygor logiczny, prostota, uniwersalność zastosowania, oryginalność, niespodziewane rozwiązanie ${ }^{15}$. Dla Davida Ruelle,

piękno w matematyce związane jest z odkrywaniem ukrytej prostoty i złożoności, które wspótistnieją w bardzo jednoznacznej logicznej strukturze istniejącej w przedmiocie badań ${ }^{16}$.

Nathalie Sinclair we własnych doświadczeniach czy przeżyciach estetycznych w tym zakresie ujmuje to w sposób następujący:

drugi sposób dowodzenia przyniósł (...) inny rodzaj satysfakcji estetycznej. Udało mi się przeprowadzić dowodzenie, które było bardziej ogólne i krótsze niż poprzednie, w moim dążeniu do zwięzłości. Odczuwałam także przyjemność z faktu dowodzenia, którego istotą była symetria. Poeta często dąży do zwięzłości, ale także do pewnej struktury organizacyjnej [wiersza] - zwykle poprzez rym i rytm - (...) symetria nadała mojemu dowodzeniu ten właśnie rodzaj struktury ${ }^{17}$.

Ron Aharon przedstawia tę kwestię w taki oto sposób: „niemal każdy matematyk zgodzi się, że idea matematyczna jest piękna, jeśli ujawnia jakąś zadziwiającą wewnętrzną strukturę". Podobnie jest w przypadku poezji: „poczucie piękna w poezji i matematyce wynika z naszej natychmiastowej i podświadomej reakcji na ukrytą strukturę"18. Jak napisał Godfrey Harold Hardy:

matematyk, podobnie jak malarz czy poeta, jest twórcą wzorów... Idee [matematyczne], podobnie jak kolory czy słowa, muszą łączyć się w harmonijny sposób. Piękno stanowi pierwszy test: brzydka matematyka nie znajdzie sobie miejsca $(. . .)^{19}$ (Ulianov Montano zadaje jednak pytanie: „jaka jest różnica między piękną i brzydką matematyką?" 20).

${ }^{13}$ Tamże, s. 53.

${ }^{14}$ J.D. Phillips, Mathematics as an Aesthetic Discipline, Humanistic Mathematics Network Journal, 1995, Issue 12, s. 18; https:// core.ac.uk/download/pdf/148361107.pdf.

${ }_{15}$ Por. V.A. Testov, Beauty in Mathematics: Symmetry and Fractality, Open Access Book, 2020, s. 2, adres internetowy: https://www.researchgate.net/publication/340946548_Beauty_ in_Mathematics_Symmetry_and_Fractality/link/5ea6e74f92851c1a90735fc3/download, s. 2.

${ }^{16}$ D. Ruelle, The Mathematician's Brain, Princeton 2007, s. 129.

${ }^{17}$ N. Sinclair, Mathematics and Beauty, s. 61.

${ }_{18}$ R. Aharoni, Mathematics, poetry and beauty, Journal of Mathematics and the Arts, 2014, 8, 1-2, s. 6 .

${ }^{19}$ J.D. Phillips, Mathematics as an Aesthetic Discipline, s. 18.

${ }^{20}$ U. Montano, Explaining Beauty, s. 3. 
Nathalie Sinclair pisze o tych problemach w nieco odmienny sposób. Uważa, iż estetyczny wymiar racjonalności matematyki opiera się na ,jasności, konsekwencji (...), spójności". Jest to zupełnie inna estetyka, niż ta, która dominuje $\mathrm{w}$ sztuce ${ }^{21}$. Jak już pisano bowiem, większość matematyków ceni „równowagę, harmonię, porządek”" 22. Le Lionnais rozróżnia między klasycznymi i romantycznymi formami piękna w matematyce. Pierwsza odwołuje się do idei prostoty, regularności i "harmonijnie zaaranżowanych struktur" (mogą je uosabiać figury geometryczne). $Z$ kolei, piękno romantyczne ma związek z „ekscentrycznością", polegającą na dowodzeniu, które nie ma charakteru bezpośredniego, niekiedy nie przynosi oczekiwanych rezultatów, ale ostatecznie pomaga w odnalezieniu właściwego rozwiązania ${ }^{23}$.

Wskaźniki piękna i kryteriów estetycznych przestają jednak oczywiście „działać” w sytuacji, kiedy teoria, twierdzenia lub wyniki badań nie spełniają kryterium prawdziwości ${ }^{24}$ (nie mają przecież wówczas sensu). James McAllister uważa, że poczucie estetyczności czy piękna przetrwa jedynie w sytuacji, gdy teoria lub odkrycie odniosą „empiryczny sukces” 25. „Mówi się, że dowodzenie jest piękne, gdy ujawnia nam tajemnicę twierdzenia, uzmysławia nam nieuchronność twierdzenia, które jest dowodzone"26. Można w tym miejscu odwołać się do jednej z „odwiecznych” tez, iż piękno jest atrybutem prawdy. Znakomicie ujął to Robbert Dijkgraaf, amerykański matematyk i fizyk, który stwierdził: „piękno równań matematycznych jest w sposób oczywisty związane $\mathrm{z}$ ich władzą skutecznego uchwycenia prawdy $(\ldots)^{\prime 27}$. Jednakże, aby raz jeszcze odwołać się do Jamesa W. McAllistera, uważa, że w przypadku odmiennych teorii, które przy zastosowaniu obiektywnych standardów są jednakowo uprawomocnione (w odniesieniu do jakiegoś problemu badawczego), wybór jednej z nich opiera się na wskaźnikach estetycznych, związanych z poczuciem piękna. Kiedy „rywalizujące teorie wydają się być jednakowo prawdziwe", to wówczas wybiera się "tę najpiękniejszą"28.

Podobny sposób rozumowania, chociaż umieszczony w innym kontekście, prezentuje Robert P. Crease - na przykładzie równań. Rozpoczyna on od

${ }^{21}$ N. Sinclair, Mathematics and Beauty, s. 144.

${ }^{22}$ Tamże, s. 145.

${ }^{23}$ U. Montano, Explaining Beauty, s. XIV.

${ }^{24}$ J.W. McAllister, Truth and Beauty, s. 39.

${ }^{25}$ J.W. McAllister, Beauty and Revolution, s. 66.

${ }^{26}$ G.-C. Rota, The Phenomenology of Mathematical Beauty, May, 1997, 111, 2, Proof and Progress in Mathematics; korzystano ze zmienionej wersji internetowej zamieszczonej pod adresem: http://www.liceogiuliocesare.it/public/documenti/Rota_Phenomenology_Mathematical_Beauty.pdf, s. 13.

${ }_{27}^{27}$ R. Dijkgraaf, Truth and Beauty. The Role of Aesthetics in Mathematics and Physics, Architectural Design, September 2019, 89(5), s. 23.

${ }^{28}$ J. McAllister, Truth and Beauty, s. 30. 
stwierdzenia, iż kilka równań uzyskało „status gwiazd”, a to dlatego, że są powszechnie rozpoznawalne, ze względu na swoją formę. Natomiast piękno, według tego autora, znajduje się w tych równaniach, które mają największe znaczenie ${ }^{29}$. Stwierdza on, że piękno nie może odnosić się do „elegancji” wizualnej wzorów, ale do głębi, którą posiadają, do zdolności wyjaśniania fenomenów i zjawisk oraz roli w rozwoju dyscypliny ${ }^{30}$. Podobnie jak wielu innych matematyków, za jedno z najpiękniejszych w historii uważa on równanie Eulera $1+\mathrm{e}^{\mathrm{i} \Pi}=0$ - właśnie $\mathrm{z}$ uwagi na swoją głębię. Przytacza przekonanie brytyjskiego matematyka Keitha Devlina, iż równanie to stanowi „matematyczną analogię do obrazu Mona Lisa Leonarda da Vinci lub statui Dawida Michała Anioła". Z kolei, amerykański fizyk i matematyk Paul Nahin określił je mianem "złotego standardu piękna matematycznego" ${ }^{31}$. Według Roberta Crease'a, równanie Eulera $1+\mathrm{e}^{\mathrm{in}}=0$ stworzyło podstawy pod nową konceptualizację matematyki jako nauki - i stąd jej piękno ${ }^{32}$.

Oczywiste jest również i to, że nie każdy potrafi dostrzec piękno czy estetyczność wzorów, twierdzeń lub dowodów matematycznych. W tym kontekście podważa się niekiedy prostotę jako kryterium estetycznego. „Piękno jakiegoś matematycznego fragmentu jest często wiązane ze skrótowością twierdzenia lub dowodzenia (...) Wiele pięknych argumentacji jest rozwlekłych $(\ldots)^{\prime \prime}$. Stąd, to posiadanie wiedzy matematycznej jest warunkiem wstępnym zrozumienia matematyki. Przy tym „dowodzenie jest uznawane za piękne jedynie przez takie osoby, które są świadome uprzednich, nieporadnych dowodzeń"33.

Podobnie problem ten ujmuje Gian-Carlo Rota, pisząc, iż mimo że „większość dowodzeń jest długich i wymaga posiadania rozległej wiedzy”, to nieustannie eksponuje się "taki sposób [ujmowania] matematycznego piękna, jak gdyby stanowiły one (...) nagły błysk po wymianie żarówki"34. I kontynuuje dalej:

Niekiedy twierdzenie jest prezentowane jako „klejnot koronny” w kontekście teorii. Jednakże kiedy twierdzenia matematyczne z odmiennych przestrzeni są nawleczone razem i prezentowane jako „sznur perel”, to mogą być docenione jedynie przez tych, którzy już wcześniej je znali ${ }^{35}$.

${ }^{29}$ R.P. Crease, The Beauty of Equations, Proceedings of Bridges 2013: Mathematics, Music, Art, Architecture, Culture, adres internetowy: https://archive.bridgesmathart.org/2013/bridges2013-19.pdf, s. 19.

${ }^{30}$ Tamże, s. 20-22.

31 Tamże, s. 23.

32 Tamże.

${ }^{33}$ G.-C. Rota, The Phenomenology, s. 10.

${ }^{34}$ Tamże, s. 11.

35 Tamże. 
Taki sposób myślenia koreluje z poglądami znanego izraelskiego matematyka Doron Zeilbergera, który w przemówieniu z okazji dziewięćdziesięciolecia urodzin amerykańskiego matematyka i filozofa Reubena Hersha całkowicie zakwestionował tezę, iż to prostota wzoru lub dowodzenia stanowi źródło piękna w matematyce. Oto, przytoczył on wyniki eksperymentu, w którym poproszono piętnastu matematyków o klasyfikację sześćdziesięciu słynnych równań według tego kryterium, jakim jest „piękno”. Za najpiękniejszy uznano wzór stworzony przez jednego z najwybitniejszych matematyków i fizyków ze wszystkich, wspomnianego już Leonharda Eulera (autora przełomowych odkryć odnoszących się między innymi do rachunku różniczkowego i całkowego oraz teorii grafów). Jak już podano wyżej, wzór ten ma następującą postać: $1+\mathrm{e}^{\mathrm{i} I}=0$. Z kolei, za "najbrzydszy” uznano ten, który stworzył genialny indyjski matematyk Srinivasa Ramanujan: $1 \Pi=2 \sqrt{ } 2$ Xळ k $=0(1103+$ 26390k) (1/4)k (1/2)k (3/4)k k! $3 \cdot 1994 k+2$. Nie będę nawet próbował wnikać $\mathrm{w}$ istotę oraz wkład tych wzorów w rozwój matematyki (artykuł ten pisany jest przez humanistę, głównie dla humanistów). Doron Zeilberger stwierdził z przekonaniem i sarkazmem, iż „«W oczach Boga» formuła Ramanujana jest piękniejsza niż Eulera”, która jest wręcz „trywialna” w porównaniu z głębią i bogactwem możliwości, jakie daje skomplikowany pierwszy wzór ${ }^{36}$.

Oczywiście, nie wszyscy akceptują ideę piękna i estetyki w matematyce. Twierdzi się, że szacowania w zakresie piękna są subiektywne, co oznacza, że są "niekompatybilne z normami racjonalności”, które leżą u podstaw matematyki ${ }^{36}$. Kryteria piękna i brzydoty pozostają w sprzeczności z kryteriami logicznymi i empirycznymi ${ }^{37}$. Zauważa się, że obiektywizm i racjonalność to pojęcia fundamentalne dla matematyki, jej sposobów dowodzenia i budowania teorii. Cel stanowi uzyskanie "czystej” wiedzy, która jest uniwersalnie weryfikowalna i nie może być podatna na żadne „subiektywne interpretacje”, w żadnym kontekście psychologicznym (nie mówiąc już o politycznym) ${ }^{38}$. Matematyka jest więc neutralna.

Z kolei Gian-Carlo Rota pisze krytycznie:

Po pierwsze, rzadko występuje zgoda co do tego, które twierdzenia lub dowodzenia są piękne. Po drugie, celem badań matematycznych rzadko jest poszukiwanie piękna. Istotą matematyki jest rozwiązywanie problemów i tworzenie nowych teorii, a nie wytwarzanie pięknych twierdzeń lub dowodzeń ${ }^{39}$.

${ }^{36}$ D. Zeilberger, What is Mathematics and What Should be, Dedicated to Reuben Hersh on his 90th birthday, tekst umieszczony pod adresem internetowym: https://arxiv.org/pdf/ 1704.05560.pdf, s. 8-9.

37 U. Montano, Explaining Beauty, s. 15.

${ }^{38}$ Tamże, s. 16.

${ }^{39}$ Por. rozważania: N. Sinclair, Mathematics and Beauty, s. 142. 
Warto jednak dodać, że kategoria piękna i estetyki dotycząca matematyki znalazła swoje miejsce $\mathrm{w}$ analizach metod kształcenia w zakresie tego przedmiotu. W odniesieniu do uczenia się matematyki, Leslie Dietiker stwierdza, iż

wbrew powszechnie przyjętemu założeniu, że uprawianie matematyki stanowi stricte racjonalną aktywność, to [w rzeczywistości] doświadczenia matematyczne mogą mieć charakter transformatywny, pełen nieodpartych impulsów i antycypacji ${ }^{40}$.

Przechodzenie od jednego do drugiego etapu w abstrakcyjnym rozumowaniu może być oparte na pewnym płynnym i przewidywalnym rytmie, o charakterze wręcz narracyjnym ${ }^{41}$. Jak pisze Arezoo Islam, istotą nauczania matematyki powinno być rozwijanie „wrażliwości na piękno matematyki” oraz „estetyczny wymiar tej dyscypliny" ${ }^{42}$. Należy przekonać dzieci, że matematyka nie polega na "zimnym” i "pozbawionym emocji poszukiwaniu prawdy"; przeciwnie, matematyczne dowodzenia mogą być pełne "piękna" $\mathrm{i}$,"elegancji" 43 .

Warto dodać, że podobna w swojej istocie dyskusja ma miejsce $\mathrm{w}$ odniesieniu do piękna i estetyki w fizyce, w której zresztą matematyka ma ogromne zastosowanie. Eugene Wigner pisał o „cudzie zastosowania języka matematyki do formułowania praw fizyki" ${ }^{44}$, z kolei Albert Einstein stwierdził: ,jak to jest możliwe, że matematyka, która jest wytworem ludzkiego umysłu niezależnym od doświadczenia w tak doskonały sposób dopasowuje się do (...) fizycznej rzeczywistości?" ${ }^{45}$. I w centrum dyskusji w fizyce znajduje się właśnie teoria Einsteina. Holenderski fizyk Hendrik Antoon Lorentz pisał o niej w następujący sposób: „Teoria względności ma najwyższy stopień jakości estetycznej: każdy miłośnik piękna musi życzyć sobie, aby była prawdziwa"46. Prawda i piękno w teorii Einsteina współistnieją ze sobą. To pierwsze pojęcie odnosi się w przypadku odkryć Alberta Einsteina do „zewnętrznych faktów, a to drugie do «naturalności» i «logicznej prostoty» pojęć i ich wzajemnych związków, co wszystko razem konstytuuje podstawowe zasady teorii" ${ }^{47}$. Można tutaj przytoczyć również, odnoszące się do teorii względności, przekonanie Paula Diraca, iż jej „wielkie piękno” jest bardziej znaczące, niż potwierdzające ją "dowody

${ }^{40}$ G.-C. Rota, The Phenomenology, s. 9.

${ }^{41}$ L. Dietiker, What Mathematics Education Can Learn from Art: The Assumptions, Values,

and Vision of Mathematics Education, Journal of Education, 2015, 195, 1, s. 3.

${ }^{42}$ Tamże, s. 5.

${ }^{43}$ W. Higginson, Foreward, w: N. Sinclair, Mathematics and Beauty, s. VIII.

${ }^{44}$ Tamże, s. 8.

45 A. Islam, A match not made in heaven: on the applicability of mathematics in physics, Synthese, 2017, 194(12), s. 4940.

${ }^{46} \mathrm{M}$. Livio, Is God a Mathematician?, s. 1.

47 J. McAllister, Truth and Beauty, s. 28. 
empiryczne" ${ }^{\prime 8}$. Z kolei, laureat Nagrody Nobla w dziedzinie fizyki Subrahmanyan Chandrasekhar przytacza słowa Ludwiga E. Boltzmanna, który pisze $\mathrm{o}$ „formalnej elegancji” niektórych wzorów fizycznych ${ }^{49}$. Również i on uważa, że teoria względności Einsteina odwołuje się do naszych zmysłów estetycznych i uznawana jest za piękną ${ }^{50}$ (sam Einstein był przekonany, że nie można uciec od „magii” jego teorii ${ }^{51}$ ). Z drugiej strony, laureat Nagrody Nobla w fizyce Steven Weinberg stwierdził: „fizyk, który twierdzi, że teoria jest piękna nie wyraża tego samego, co oznacza stwierdzenie, iż obraz, utwór muzyczny czy poetycki jest piękny" 52. Zapewne ma to związek z faktem, iż fizyczne „,abstrakcje" stanowią odkrycie realnie istniejących prawidłowości. Jak napisał Alain Hache: „piękno fizyki związane jest z jej zdolnością do redukowania bardzo złożonych zjawisk do kilku prostych zasad i równań" 53 .

Z kolei Cain S. Todd pisze: „Wielu przyrodników i matematyków zdaje się zakładać, że teorie i dowodzenia są piękne, ponieważ w sposób odpowiedni opisują bądź odzwierciedlają piękno świata" ${ }^{54}$. Można tutaj przywołać piękne słowa Henri Poincarégo:

Naukowiec nie bada natury, ponieważ jest to użyteczne; bada ją, ponieważ zachwyca się nią, a zachwyca się nią, ponieważ jest ona piękna... to właśnie intelektualne piękno czyni inteligencję nieuniknioną i silną ${ }^{55}$.

W wielu przypadkach teorie są uważane za estetyczne, kiedy sprawdzają się empirycznie. W odniesieniu do „pięknej teorii”, brytyjski fizyk-teoretyk Paul Dirac stwierdził: „Jeśli ta teoria jest rzeczywiście piękna, to z pewnością będzie stanowiła odpowiedni model dla ważnych zjawisk fizycznych", które realnie istnieją $\mathrm{w}$ przyrodzie $\mathrm{e}^{56}$.

Co ciekawe, niemal cała współczesna dyskusja dotycząca piękna i estetyki teorii naukowej odnosi się do nauk ścisłych, szczególnie matematyki i fizyki. Trudno znaleźć w literaturze naukowej odniesienia do piękna czy estetyczności teorii socjologicznej, psychologicznej, czy teorii historycznej (choć, oczywiście, w ramach filozofii trwa niekończąca się dyskusja na temat

48 Tamże, s. 29.

49 Podaję za: J.W. McAllister, Beauty and Revolution, s. 15.

${ }^{50}$ S. Chandrasekhar, Truth and Beauty. Aesthetics and Motivations in Science, Chicago 1987, s. 76.

51 Tamże, s. 82.

${ }^{52}$ Tamże, s. 76.

${ }^{53}$ U. Montano, Explaining Beauty, s. 17.

${ }^{54}$ A. Hache, Physics of Hockey, Baltimore 2002, s. IX.

55 C.S. Todd, Unmasking the Truth Beneath the Beauty: Why the Supposed Aesthetic Judgements Made in Science May Not Be Aesthetic at All, International Studies in the Philosophy of Science, 2008, 22, 1, s. 62.

${ }^{56}$ Podaję za: M. Girod, C. Rau, A. Schepige, Appreciating the Beauty of Science Ideas: Teaching for Aesthetic Understanding, Science Education, 2003, 87, s. 575. 
istoty i kryteriów piękna zarówno w odniesieniu do pojęć, jak i rzeczywistości). Nietrudno zauważyć, że kategoria piękna w badaniach naukowych występuje także w naukach społecznych i humanistycznych, ale jako przedmiot badań, a nie kryterium odnoszące się do teorii. Dotyczy na przykład postrzegania piękna (także twarzy lub ciała) - w psychologii, piękna poezji - w polonistyce, czy na przykład rekonstrukcji historycznej ewolucji piękna w sztuce (z kolei na przykład w biologii pisze się teksty na temat darwinowskiej teorii piękna ${ }^{57}$, czy o pięknie roślin itp..$\left.^{58}\right)$. Nie pisze się natomiast - powtórzę zatem - o "pięknych teoriach” w dziedzinie nauk społecznych czy humanistycznych. Pewnym wyjątkiem jest tutaj prawo, gdzie można znaleźć wiele tekstów poświęconych „pięknu prawa”, czy „estetyce prawa”, choć zwykle w kontekście filozoficznym ${ }^{59}$. Osobiście jako socjolog edukacji mogę potwierdzić, iż niektóre ze znanych mi teorii wywoływały u mnie odczucie „estetycznej elegancji” w trakcie prowadzonych przeze mnie analiz i rozważań. Odczucie to wynikało z ujmującej prostoty tych teorii, która pozwalała - z wykorzystaniem bardzo żywotnych intelektualnie pojęć i kategorii na zrozumienie/opisanie bardzo niekiedy skomplikowanych procesów czy zjawisk społecznych. Myślę tutaj na przykład o teoriach Talcotta Parsonsa, Pierre'a Bourdieu, czy Michaela Foucaulta. Z pewnością, odkrywanie przy tym rzeczywistości, myślenie oraz tworzenie w naukach społecznych i humanistycznych może także dostarczać przeżyć estetycznych, w tym również doznawania poczucia piękna.

\section{BIBLIOGRAFIA}

Aharoni R., Mathematics, poetry and beauty, Journal of Mathematics and the Arts, 2014, 8, $1-2$.

Alsina C., Nelsen R.B., Charming Proofs: A Journey Into Elegant Mathematics, printed in U.S., 2010.

Baidou A., The Praise of Mathematics, Cambridge 2016.

Barković D., Challenges of Interdiscyplinary Research, Interdiscyplinary Management Research, 2010, 6.

Bloch C., Passion and Paranoia: Emotions and the Culture of Emotions in Academia, London New York 2016.

Bos H.J.M., Lectures in the History of Mathematics, Providence 1993.

Chandrasekhar S., Truth and Beauty. Aesthetics and Motivations in Science, Chicago 1987.

57 A. Stakhov, The Mathematics of Harmony: From Euclid to Contemporary Mathematics and Computer, Singapore 2009, s. 615-616.

58 D. Dutton, A Darwinian Theory of Beauty, Philosophy and Literature, October 2014, 38, $1 \mathrm{~A}$.

59 J. Dong, Study on the formal beauty of plants in interior design, Advances in Social Science, Education and Humanities Research (ASSEHR), volume 2062018 International Conference on Advances in Social Sciences and Sustainable Development, ASSSD 2018, adres internetowy: https://www.atlantis-press.com/proceedings/asssd-18/25894466 
Crease R.P., The Beauty of Equations, Proceedings of Bridges 2013: Mathematics, Music, Art, Architecture, Culture, adres internetowy: https://archive.bridgesmathart.org/2013/ bridges2013-19.pdf

Dietiker L., What Mathematics Education Can Learn from Art: The Assumptions, Values, and Vision of Mathematics Education, Journal of Education, 2015, 195, 1.

Dijkgraaf R., Truth and Beauty. The Role of Aesthetics in Mathematics and Physics, Architectural Design, September 2019, 89(5).

Dong J., Study on the formal beauty of plants in interior design, Advances in Social Science, Education and Humanities Research (ASSEHR), volume 2062018 International Conference on Advances in Social Sciences and Sustainable Development, ASSSD 2018, adres internetowy: https://www.atlantis-press.com/proceedings/asssd-18/25894466

Dutton D., A Darwinian Theory of Beauty, Philosophy and Literature, October 2014, 38, 1A.

Gearey A., Law and Aesthetics, Oxford 2001.

Girod M., Rau C., Schepige A., Appreciating the Beauty of Science Ideas: Teaching for Aesthetic Understanding, Science Education, 2003, 87.

Hache A., Physics of Hockey, Baltimore 2002.

Islam A., A match not made in heaven: on the applicability of mathematics in physics, Synthese, 2017, 194(12).

Livio M., Is God a Mathematician?, New York 2009.

Manderson D., Songs without Music: Aesthetic Dimensions of Law and Justice, Berkeley 2000.

McAllister J.W., Beauty and Revolution in Sience, New York 1996.

McAllister J.W., Mathematical beauty and the evolution of the standards of mathematical proof, [w:] The Visual Mind II, red. M. Emmer, Cambridge 2005.

McAllister J.W., Truth and Beauty in Scientific Reason, Synthesis, 1989, 78; adres internetowy: https://openaccess.leidenuniv.nl/bitstream/handle/1887/8123/9_057_017. pdf;sequence $=1$.

Melosik Z., Pasja i tożsamość naukowca. O władzy i wolności umystu, Poznań 2019.

Montano U., Explaining Beauty in Mathematics: An Aesthetic Theory of Mathematics, Cham 2014.

Phillips J.D., Mathematics as an Aesthetic Discipline, Humanistic Mathematics Network Journal, 1995, Issue 12; https:/ / core.ac.uk/download/pdf/148361107.pdf.

Rota G.-C., The Phenomenology of Mathematical Beauty, May, 1997, 111, 2, Proof and Progress in Mathematics; korzystano ze zmienionej wersji internetowej zamieszczonej pod adresem: http://www.liceogiuliocesare.it/public/documenti/Rota_Phenomenology_ Mathematical_Beauty.pdf

Ruelle D., The Mathematician's Brain, Princeton 2007.

Sinclair N., Mathematics and Beauty. Aesthetic Approach to Teaching Children, New York 2006.

Stakhov A., The Mathematics of Harmony: From Euclid to Contemporary Mathematics and Computer, Singapore 2009.

Testov V.A., Beauty in Mathematics: Symmetry and Fractality, Open Access Book, 2020; adres internetowy: https://www.researchgate.net/publication/340946548_Beauty_in_ Mathematics_Symmetry_and_Fractality/link/5ea6e74f92851c1a90735fc3/download

Todd C.S., Unmasking the Truth Beneath the Beauty: Why the Supposed Aesthetic Judgements Made in Science May Not Be Aesthetic at All, International Studies in the Philosophy of Science, 2008, 22, 1 .

Zeilberger D., What is Mathematics and What Should be, Dedicated to Reuben Hersh on his 90th birthday, tekst umieszczony pod adresem internetowym: https://arxiv.org/ pdf/1704.05560.pdf 